\title{
大别造山带三叠纪低级变质的新元古代火成岩: 俯冲陆壳表层拆离折返的岩片
}

\author{
刘贻灿 ${ }^{*}$, 李远, 刘理湘, 古晓锋, 邓亮鹏, 刘佳 \\ 中国科学院壳幔物质与环境重点实验室, 中国科学技术大学地球和空间科学学院, 合肥 230026 \\ *联系人, E-mail: liuyc@ustc.edu.cn \\ 2013-05-15 收稿, 2013-06-14 接受, 2013-08-07 网络版发表 \\ 国家重点基础研究发展计划(2009CB825002)和国家自然科学基金(41273036, 40973043)资助
}

\begin{abstract}
摘要 野外地质调查、岩石学观察以及地球化学和锆石 U-Pb 年代学研究结果表明, 大别造山带 中存在多种三叠纪低级变质的新元古代花岗岩和基性岩. 其中北淮阳带西段原“定远组”奥陶纪 变质火山岩中新元古代原岩的低级变质岩片至少包含 3 种岩石, 即 720 760 Ma 侵位的变质花岗 岩和变玄武岩以及 $630 \mathrm{Ma}$ 侵位的变质辉长岩. 而超高压变质带中则主要为 780 800 Ma 侵位的 变质花岗岩和变基性岩, 局部经历了 770 Ma变质作用和 750 Ma 热事件改造. 这些变质火成岩 的原岩侵位时代与北淮阳带东段庐镇关杂岩的侵位时代一致. 北淮阳带西段低级变质的新元古 代火成岩都经过了强烈的三叠纪构造变形和 $240 \mathrm{Ma}$ 绿穷角闪岩相变质作用, 以构造透镜体或岩 片形式产于变质的奥陶纪火山岩带(原“定远组”)中. 它们的 $\mathrm{Pb}$ 同位素组成类似于具有上地壳属性 的中大别超高压正变质岩, 在原岩年龄上与华南陆块北缘湖北随州- 本阳一带发育的两期大规模 新元古代中、晚期基性岩墙群和花岗岩的侵位时代、大别山超高压带中低级变质火成岩以及超高 压正变质岩的原岩年龄一致。这些成果进一步证明, 大别山低级变质的新元古代火成岩是三叠纪 华南陆块深俯冲初始阶段陆壳表层被拆离折返的岩片, 并在南北陆块汇聚、碰撞造山过程中被推 覆到华北陆块南缘的古生代变质岩系之上或以飞来峰的形式存在于超高压变质带中.
\end{abstract}

关键词

低级变质

火成岩

新元古代 大陆碰撞 陆壳拆离
柯石英和金刚石等超高压变质矿物的发现，已 证明陆壳岩石能俯冲到 $>120 \mathrm{~km}$ 的地幔深度并折返 至地表 ${ }^{[1,2]}$. 但是, 陆壳岩石的俯冲与折返过程, 却 一直是大陆动力学研究方面的热点和前沿问题之一. 其中, 深俯冲陆壳岩石的折返机制又是长期争议的 焦点, 并已提出多种解释模型 ${ }^{[3,4]}$.

大别造山带因含柯石英和金刚石超高压变质带 出露的规模巨大和岩石类型齐全而闻名于世, 并为 研究大陆碰撞造山带的形成和演化过程以及超高压 岩石的形成与折返机制等提供了重要的天然实验室. 大别造山带位于华北和华南两个大陆板块之间, 是 三叠纪华南板块向华北板块之下俯冲形成的碰撞型
造山带. 大别造山带主要包括宿松变质带、南大别低 温/超高压榴辉岩相变质带、中大别中温/超高压榴辉 岩相变质带、北大别高温/超高压榴辉岩相杂岩带及 北淮阳带等构造岩石单位 ${ }^{[5]}$. 其中榴辉岩只出现在 南大别、中大别和北大别带, 而宿松变质带和北淮阳 带是两个相对低级的变质单元. 它们之间依次分别 被太湖-山龙、花凉亭-弥陀、水吼-五河及磨子潭-晓 天等大型断裂带或韧性剪切带所分割(图 1).

近年来, 大别-苏鲁造山带中陆续发现一些低级 变质的新元古代岩石, 甚至具有三叠纪变质年龄记 录, 如董树文等人 ${ }^{[8]}$ 、高天山等人 ${ }^{[9]}$ 和 Tang 等人 ${ }^{[10]}$ 分别根据大别山超高压带中的港河绿片岩相岩石有 


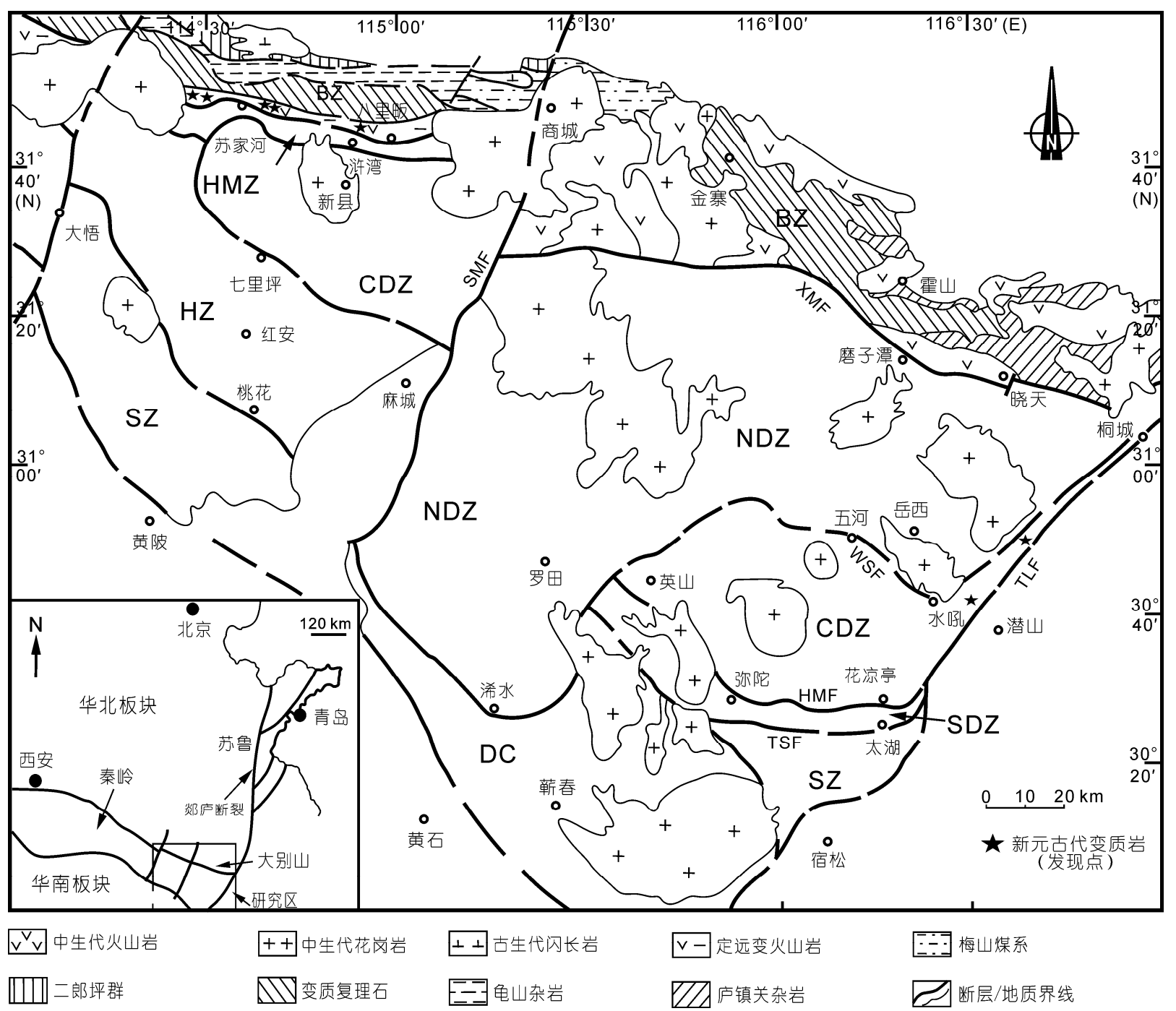

图 1 大别造山带的地质简图(据文献[7]修改)及低级变质的新元古代火成岩发现点

BZ, 北淮阳带; NDZ, 北大别杂岩带; CDZ, 中大别超高压变质带; SDZ, 南大别低温榴辉岩带; SZ, 宿松变质带; HMZ, 浒湾混杂岩带; HZ, 红安低温榴辉岩带; DC, 角闪岩相大别杂岩; XMF, 晓天-磨子潭断裂; WSF, 五河-水吼断裂; HMF, 花凉亭-弥陀断裂; TSF, 太湖山龙断裂; TLF，郯庐断裂; SMF，商城-麻城断裂

232.2 \pm 8.3 Ma Rb-Sr 年龄和 770 780 Ma 的 Ar-Ar 年 龄记录以及锆石 $\mathrm{U}-\mathrm{Pb}$ 年龄指示的原岩时代为 760 $800 \mathrm{Ma}$ ，苏鲁超高压带西北侧(胶北)的粉子山群中不 纯大理岩的原岩时代为 $786 \pm 67 \mathrm{Ma}$ 和变质时代为 $240 \pm 44 \mathrm{Ma}$, 认为它们属于华南陆块北缘的一部分并 且参与了华南陆块的印支期俯冲，但未经历超高压 变质作用. 另外, 前期研究 ${ }^{[6,11 ~ 18]}$ 还表明, 北淮阳带 东段庐镇关杂岩中花岗片麻岩和变质辉长岩、北淮阳 带西段原“定远组”变质火山岩中分布的变质花岗岩 和变质辉长岩以及苏鲁地区五莲花岗片麻岩等的形 成时代为新元古代. 庐镇关杂岩中花岗片麻岩的角

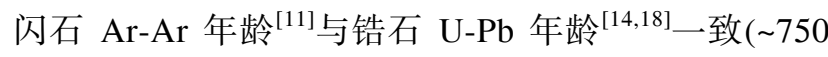
$\mathrm{Ma})$, 表明它们在新元古代以后的变质温度都低于角 闪石的 $\mathrm{Ar}-\mathrm{Ar}$ 封闭温度 $\left(<500{ }^{\circ} \mathrm{C}\right)$ 以及它们以低绿片岩 相变质作用为主, 因而认为它们是未参与深俯冲而 是被刮下来的“构造加积楔”[6]. 这些低级变质花岗岩 和变基性岩的形成时代与超高压带中榴辉岩和正片 麻岩的原岩时代 ${ }^{[7,19 ~ 23]}$ 以及华南陆块北缘湖北随州㤟阳等地发育的大规模新元古代中、晚期基性岩墙群 和花岗岩的时代 ${ }^{[24 ~ 26]}$ 一致, 指示它们可能有类似的 形成大地构造背景即形成于华南陆块北缘的裂谷环 境, 由此证明这些新元古代低级变质花岗岩和变基 
性岩等是在大别山陆壳深俯冲初期最早被拆离、解耦 的低级变质岩片, 并在南、北陆块汇聚、碰撞过程中 被推覆到华北陆块南缘古生代变质岩系之上(如北淮 阳带)或以飞来峰的形式存在于超高压带中 (如港

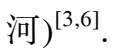

北淮阳带西段(商-麻断裂以西), 主要由原信阳 群南湾组(变质复理石)和龟山组(又称龟山杂岩)、原 苏家河群中定远组和原石炭纪梅山群等岩石单位以 及变质火成岩、古生代闪长岩等花岗岩类岩石和中生 代岩石等组成. 其中, 新元古代低级变质(橄榄)辉长 岩沿桐柏-桐城断裂(研究区为定远-苏家河-八里畈断 裂)的北侧, 从千斤河棚乡王母观向西经苏家河至信 阳南部西双河和桐柏一带呈大小不等的岩块或岩片 出露, 千斤河棚乡向东经吴陈河乡至八里畈乡一带 也有类似岩石断续分布. 其围岩为原“定远组”变质 火山岩, 目前表现为含石榴子石绿帘云母石英片岩. 二者之间为断层接触 ${ }^{[16]}$. 其南、北分别与湤湾混杂岩 带和“南湾组”变质复理石等构造岩石单位相邻, 再 向南为新县超高压变质带. 原苏家河群吘湾组中既

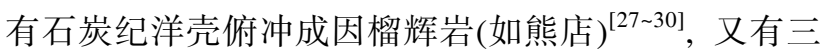
叠纪陆壳俯冲成因榴辉岩 ${ }^{[13,27,28]}$, 它们的原岩时代分 别为古生代 ${ }^{[27,28]}$ 和新元古代 ${ }^{[13,29]}$, 因而称之为湤湾 混杂岩带 ${ }^{[16,27,28,31]}$, 它的变质相及形成时代完全不同 于“定远组”即表现为绿窝角闪岩相和形成时代为奥 陶纪 ${ }^{[16,27 ~ 29,31]}$. 为了确定并查明北淮阳带西段原“定 远组”中变基性岩是否具有一致的形成时代和是否有 类似于北淮阳带东段庐镇关杂岩的变质花岗岩和变 基性岩以及大别山超高压带中是否存在低级变质花 岗岩和变基性岩等, 我们对北淮阳带西段和中大别 超高压带进行了详细的野外地质调查和系统的岩石 地球化学和锆石 U-Pb 年代学等方面研究, 结果证明 北淮阳带西段和中大别超高压带中都存在原岩为新 元古代的低级变质花岗岩和变基性岩(变质辉长岩和 变玄武岩 $)^{[32]}$ 的岩片(图 1), 为俯冲陆壳表层拆离折返 提供了证据.

\section{1 低级变质花岗岩和变基性岩的产状}

北淮阳带西段原“定远组”变质火山岩中存在 3 种低级变质的新元古代火成岩: 变质(橄榄)辉长岩、 变玄武岩和含石榴变质花岗岩 ${ }^{[16,17,32]}$. 最近, 我们 在中大别超高压带中发现低级变质花岗岩和变基 性岩 ${ }^{[32]}$.

\section{1 北淮阳带西段变质花岗岩和变基性岩}

北淮阳带西段低级变质的新元古代花岗岩和基 性岩, 目前仅发现于“定远组”变质火山岩中, 主要岩 石类型有变质辉长岩、变玄武岩和变质花岗岩 ${ }^{[16,17,32]}$.

(1) 变质辉长岩. 此类岩石在该带有大量分布. 它们的变质程度较低, 而且, 岩片的不同位置变质程 度有所差异, 如王母观“岩体”中心为橄榄辉长岩, 变 质非常弱(仍保留岩浆堆晶结构和辉长结构); 而边部 变质程度相对较强, 发育片麻状、片状构造和变余辉 长结构等, 并常含有金红石, 单斜辉石常退变为角闪 石, 斜长石大多数退变为绿帘石 + 钠长石, 金红石退 变为钛铁矿, 一些矿物发生强烈韧性变形或旋转 (如斜长石发生强烈剪切, 造成双晶被错断). 变质、 变形较强的变质辉长岩中角闪石主要沿面理分布或 呈单斜辉石的退变边. 总体表现为绿帘角闪岩相变 质作用.

(2) 变玄武岩. 目前表现为斜长角闪片岩, 常 与变质花岗岩共生, 变质、变形程度相对较强, 面理 发育, 主要矿物有角闪石、绿帘石、斜长石和榍石等, 表现为绿帘角闪岩相.

(3) (含石榴)变质花岗岩. 该类岩石出露较少, 仅发现于苏家河以东和湤湾以北的公路旁采石场. 主要矿物有钾长石、斜长石、石英、白云母、石榴子 石、角闪石和绿帘石等, 次要矿物有磁铁矿和磷灰石 等. 该类岩石已发生强烈变形, 表现为强烈面理化以 及矿物的细粒化和定向排列等(即已糜棱岩化和局部 已达到糜棱岩), 并经历了低级变质作用. 其中, 变 质的绿帘石和角闪石等矿物大致沿面理分布, 表现 为绿帘角闪岩相.

\section{2 超高压带中低级变质花岗岩和变基性岩}

根据野外地质调查, 结合室内岩石学薄片观察 和锆石 U-Pb 定年研究, 我们在中大别超高压带中龙 井关、野寨等地发现低级变质花岗岩和变基性岩 (图 1). 其中, 变基性岩主要为变玄武岩, 目前表现 为斜长角闪片岩或斜长角闪岩, 主要矿物有斜长石、 角闪石、绿帘石和金红石等; 变质花岗岩表现为块状 结构、面理不发育, 主要矿物有钾长石、斜长石、石 榴子石、角闪石、绿帘石、黑云母和白云母等. 因此, 它们的峰期变质作用都为角闪岩相. 然而, 该带中 超高压花岗片麻岩的片麻理发育并含有柯石英、绿 辉石和石榴子石等超高压榴辉岩相变质矿物(如文 
献[33]).

上述低级变质花岗岩和变基性岩明显不同于北 大别和中大别超高压正片麻岩和榴辉岩, 主要表现 在两个方面: 一是变质过程和变质程度上的差异, 前 者仅发生了绿帘角闪岩相变质作用，而超高压片麻 岩及榴辉岩则明显经受过超高压榴辉岩相变质作用 并经历了多阶段折返与减压过程、甚至高压麻粒岩相 变质作用的叠加 ${ }^{[7,23]}$; 二是锆石中变质记录的差异, 北淮阳带西段新元古代浅变质岩石中锆石为典型的 岩浆锆石, 大多数没有发生明显增生, 即使有也是非 常薄的 $(<20 \mu \mathrm{m})^{[16,17]}$, 而超高压片麻岩和榴辉岩中 锆石的阴极发光图像则显示特征的核-幔-边结构即 表现为岩浆锆石核、超高压变质幔和退变质增生边 等 ${ }^{[22,23,34]}$. 因此, 尽管北淮阳带及超高压带中低级变 质的新元古代变质花岗岩和变基性岩与大别山超高 压榴辉岩和正片麻岩的原岩时代一致, 但二者经历 的变质演化过程却明显不同.

\section{2 原岩时代和变质作用的锆石 U-Pb 年代 学制约}

\section{1 北淮阳带西段}

变质辉长岩中锆石在阴极发光(CL)图像上显示, 具有岩浆结晶环带, 为典型的岩浆锆石, 并未发育增 生边. 这些特征明显不同于北大别经过了超高压及 多期变质作用的花岗片麻岩和榴辉岩中锆石的 CL 图 像 ${ }^{[22,23]}$, 后者通常发育特征的核-幔-边结构. 因而从 另一方面证明二者可能具有不同的变质演化过程. 锆石 U-Pb 年龄结果表明: (1) 样品 06WMG-5 中具有 岩浆结晶环带的 22 个锆石核 ${ }^{206} \mathrm{~Pb} /{ }^{238} \mathrm{U}$ 谐和年龄的加 权平均值为 $631 \pm 5 \mathrm{Ma}(\mathrm{MSWD}=0.45)$; (2) 样品 06DY2-2 中具有岩浆结晶环带的 12 个锆石核 ${ }^{206} \mathrm{~Pb} /$ ${ }^{238} \mathrm{U}$ 谐和年龄的加权平均值为 $623 \pm 14 \mathrm{Ma}(\mathrm{MSWD}=$ $0.27)^{[32]}$. 因此, 北淮阳带西段两个变形较强的变质 辉长岩的形成时代分别为 $631 \pm 5$ 和 $623 \pm 14 \mathrm{Ma}$, 与以 前报道的变质橄榄辉长岩的年龄结果 $(635 \pm 5 \mathrm{Ma})^{[16]}$ 在误差范围内一致, 进一步证明北淮阳带西段原 “定远组”变质火山岩中变质辉长岩的形成时代为 \%630 Ma.

变玄武岩中锆石的 CL 图像显示, 大多数锆石呈 蜂窝状、海锦状、斑杂状结构; 少数具有核-边结构, 但核部有微弱岩浆结晶环带或已部分重结晶, 其边
部具有亮的阴极发光、低 $\mathrm{U}$ 含量, 显示变质重结晶; 还有两颗锆石, 具有弱的结晶分带和较高的 $\mathrm{Th} / \mathrm{U}$ 比, 指示为变质重结晶锆石 ${ }^{[32]}$. 因此, 该样品中锆石 $\mathrm{CL}$ 图像明显不同于变质辉长岩, 其中大部分锆石与南 大别低温榴辉岩带中片麻岩的 CL 图像 ${ }^{[35]}$ 相似, 呈海 绵状或多孔状，可能指示为流体交代重结晶形成 的 ${ }^{[35,36]}$. 锆石 U-Pb 定年结果表明: 去除明显偏离不 一致线的 3 个分析点, 由其余 8 个点得到不一致线的 上、下交点年龄分别为 $903 \pm 100$ 和 $240 \pm 43 \mathrm{Ma}$ $(M S W D=2.6)^{[32]}$. 由于接近上交点的分析点较少, 得到的上交点年龄误差较大; 一个锆石的核部给出 近于谐和的 ${ }^{206} \mathrm{~Pb} /{ }^{238} \mathrm{U}$ 年龄为 $724 \pm 5 \mathrm{Ma}$. 其余分析点 (由变质重结晶和交代重结晶锆石域给出的)集中在 下交点位置, 下交点年龄 $240 \pm 43 \mathrm{Ma}$ 与该带花岗质 糜棱岩中白云母的 $\mathrm{Ar}-\mathrm{Ar}$ 年龄 $(241.5 \pm 1.7 \mathrm{Ma})^{[23]}$ 以及 庐镇关杂岩中花岗片麻岩中白云母的 $\mathrm{Ar}-\mathrm{Ar}$ 年龄 ${ }^{[11]}$ 和胶北地块粉子山群大理岩中变质锆石时代 ${ }^{[10]}$ 一致, 记录了变玄武岩的俯冲变质时代; 而一个靠近上交 点的、近于谐和的分析点的 ${ }^{206} \mathrm{~Pb} /{ }^{238} \mathrm{U}$ 年龄为 $724 \pm 5$ $\mathrm{Ma}$ ，与共生的变质花岗岩的形成时代 $(758 \pm 12 \sim 726 \pm 6$ $\mathrm{Ma})^{[17]}$ 一致, 指示其形成时代为新元古代中期.

因此, 北淮阳带西段原“定远组”变质火山岩带 中至少发育两种不同形成时代的新元古代低级变质 岩石: 一是形成于 $630 \mathrm{Ma}$ 左右的变质(橄榄)辉长岩, 另一类是形成于 758 726 Ma 的变质花岗岩和变玄武 岩, 并经历了 $240 \mathrm{Ma}$ 绿帘角闪岩相变质作用 ${ }^{[32]}$.

\section{2 中大别超高压带}

锆石 SHRIMP 法 U-Pb 定年结果表明，中大别超 高压带中低级变质花岗岩的形成时代为 $793 \pm 11$ $795 \pm 11 \mathrm{Ma}$ 和变基性岩的形成时代为 $772 \pm 6 \mathrm{Ma}$, 并 经历了 $768 \pm 7 \mathrm{Ma}$ 的变质作用和 $746 \pm 4 \mathrm{Ma}$ 热事件改 造. 根据变基性岩中 $768 \pm 7 \mathrm{Ma}$ 的变质锆石域中金红 石、石英和角闪石等矿物包体的产出, 推测其发生的 变质条件为麻粒岩相或高角闪岩相, 类似于北大别 的罗田榴辉岩 ${ }^{[7]}$. 这些近于一致的新元古代形成时代 和变质时代可能指示, 新元古代幔源岩浆板底垫托 或岩浆底侵成因。但二者的锆石中均未发现三叠纪 变质的岩石学和年代学记录, 类似于中大别碧溪岭 未记录超高压变质作用的新元古代花岗岩 ${ }^{\left[{ }^{[7]}\right.}$ 和苏鲁 造山带中部仰口未记录超高压变质作用的新元古代 辉长岩 ${ }^{[15]}$. 岩浆侵人体在大陆俯冲过程中由于缺乏 
流体活动难以生长出变质锆石用于 $\mathrm{U}-\mathrm{Pb}$ 定年 ${ }^{[38]}$, 甚 至部分岩浆成因含水矿物在经受超高压变质时也处 于亚稳定状态 ${ }^{[37]}$. 然而, 在与低级变质花岗岩相共 生的超高压花岗片麻岩锆石中却发现柯石英、多硅白 云母、绿辉石、石榴子石和金红石等超高压榴辉岩相 变质矿物组合以及具有多期变质生长时代记录(如 $237 \pm 3,227 \pm 3$ 和 $209 \pm 4 \mathrm{Ma}$ ), 但二者具有类似的化学 成分和形成时代, 指示它们的原岩都为新元古代花 岗岩.

\section{3 岩石成因及其大地构造意义}

中大别超高压带中变基性岩全岩的 $\mathrm{SiO}_{2}$ 为 $45.72 \%$ 47.64\%, $\mathrm{MgO}$ 为 4.37\% 13.29\%以及稀土元 素球粒陨石标准化图解上没有明显的 $\mathrm{Eu}$ 异常, 表明 它们的原岩为玄武岩; 变质花岗岩的 $\mathrm{SiO}_{2}$ 为 $76.04 \%$ $77.61 \%$ 以及稀土元素球粒陨石标准化图解上有明显 的 $\mathrm{Eu}$ 负异常, 它们的原岩为花岗岩. 而该带中超高 压花岗片麻岩与低级变质花岗岩具有类似的岩石化 学成分, 结合它们的锆石特点和形成时代, 指示它们 的原岩都为新元古代花岗岩.

北淮阳带西段变基性岩有两类：一是稀土元素 球粒陨石标准化图解上有明显 Eu 正异常、另一类则 没有明显 $\mathrm{Eu}$ 异常, 反映它们的原岩分别为辉长岩和 玄武岩, 与岩相学观察结果一致 ${ }^{[32]}$. 而且, 它们的 REE 配分型式和微量元素蜘蛛网图解与分布于湖北 随州-菄阳一带分布的新元古代基性岩 ${ }^{[25]}$ 类似，表明 它们有类似的岩石成因. 根据 Sr-Nd-Pb 同位素分 析 $^{[32]}$, 北淮阳带西段变基性岩是由幔源岩浆与不同
程度的陆壳物质混合形成的，而且变质花岗岩和变 基性岩的 $\mathrm{Pb}$ 同位素组成类似于具有上地壳属性的中 大别超高压正变质岩(图 2).

综上所述, 北淮阳带西段低级变质的新元古代 火成岩的形成时代与超高压带中低级变质花岗岩和 变基性岩(本文)及超高压岩石 ${ }^{[7,19 ~ 22]}$ 的原岩时代以及 华南陆块北缘随州-疋阳等地发育的新元古代中、晚 期基性岩墙群和花岗岩的时代(640 630 和 820 710

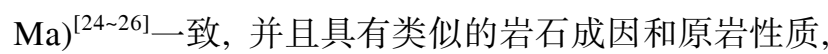
指示它们形成于华南陆块北缘的新元古代裂谷环 境 ${ }^{[15,41]}$, 可能是 Rodonia 超大陆裂解过程中岩浆活动 的产物 ${ }^{[22,43]}$. 北淮阳带西段新元古代变质岩出露于 汻湾混杂岩带以北的变质奥陶纪火山弧之中, 二者 具有不同的形成时代和原岩性质以及它们之间为断 层接触 ${ }^{[16]}$, 因此, 该带又被称为八里畈混杂岩 带 ${ }^{[13,29,44]}$. 此外, 北淮阳带变基性岩具有 240 Ma 锆石 U-Pb 年龄记录 ${ }^{[32]}$ 以及相关变质岩的云母中有 $241.5 \pm 1.7 \mathrm{Ma}$ 的 $\mathrm{Ar}-\mathrm{Ar}$ 年龄 ${ }^{[4]}$, 而白云母的 $\mathrm{Ar}-\mathrm{Ar}$ 封闭温度较低以及该带变质岩为绿帘角闪岩相-绿片 岩相 ${ }^{[27,29,31]}$, 因而它们可能是印支期华南陆块发生 深俯冲的初始阶段最早发生拆离折返的岩片, 并在 大陆碰撞过程中被推覆到华北南缘古生代变质岩系 之上.

因此，大别山北淮阳带及超高压带中新元古代 低级变质岩的发现和确定，一方面进一步指示华南 陆块北缘在新元古代中、晚期仍处于拉张环境, 发育 与两期大陆裂解事件有关的岩石学记录, 并为华南 陆块南沱和古城冰期的结束时间提供了新的制约;
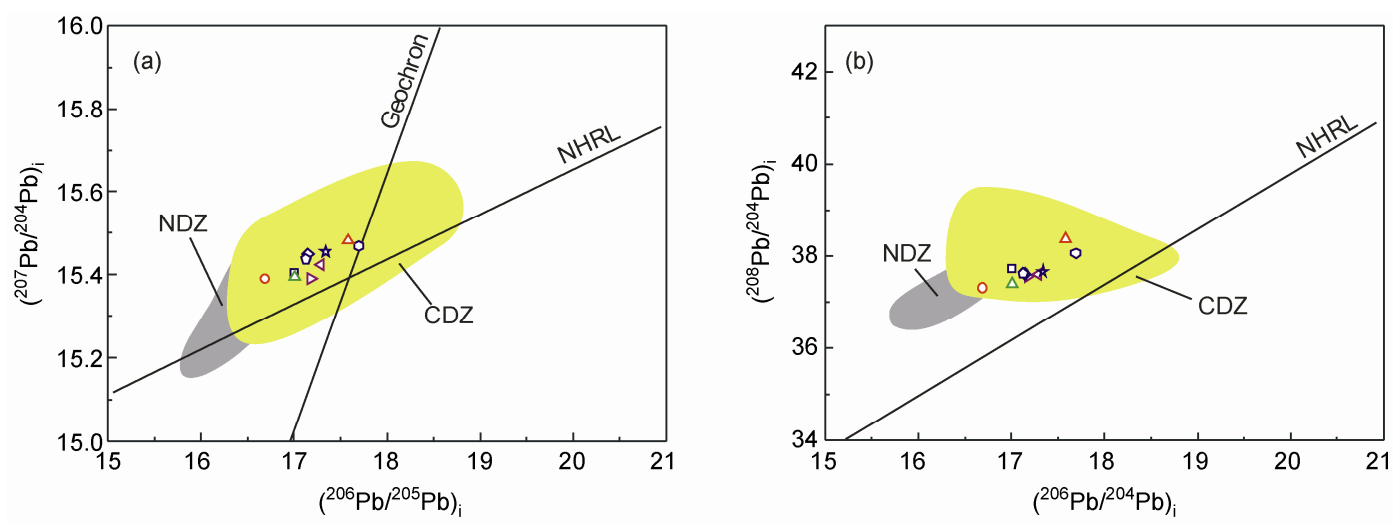

图 2 北淮阳带西段低级变质的新元古代火成岩的初始 $\mathbf{P b}$ 同位素组成 $(t=230 \mathrm{Ma}$ )图解

北大别(NDZ)和中大别(CDZ)超高正片麻岩和榴辉岩数据来自于文献 $[39,40]$. 图中红色、绿色以及紫色和蓝色符号的数据点分别代表 变质花岗岩、变玄武岩和变质辉长岩 

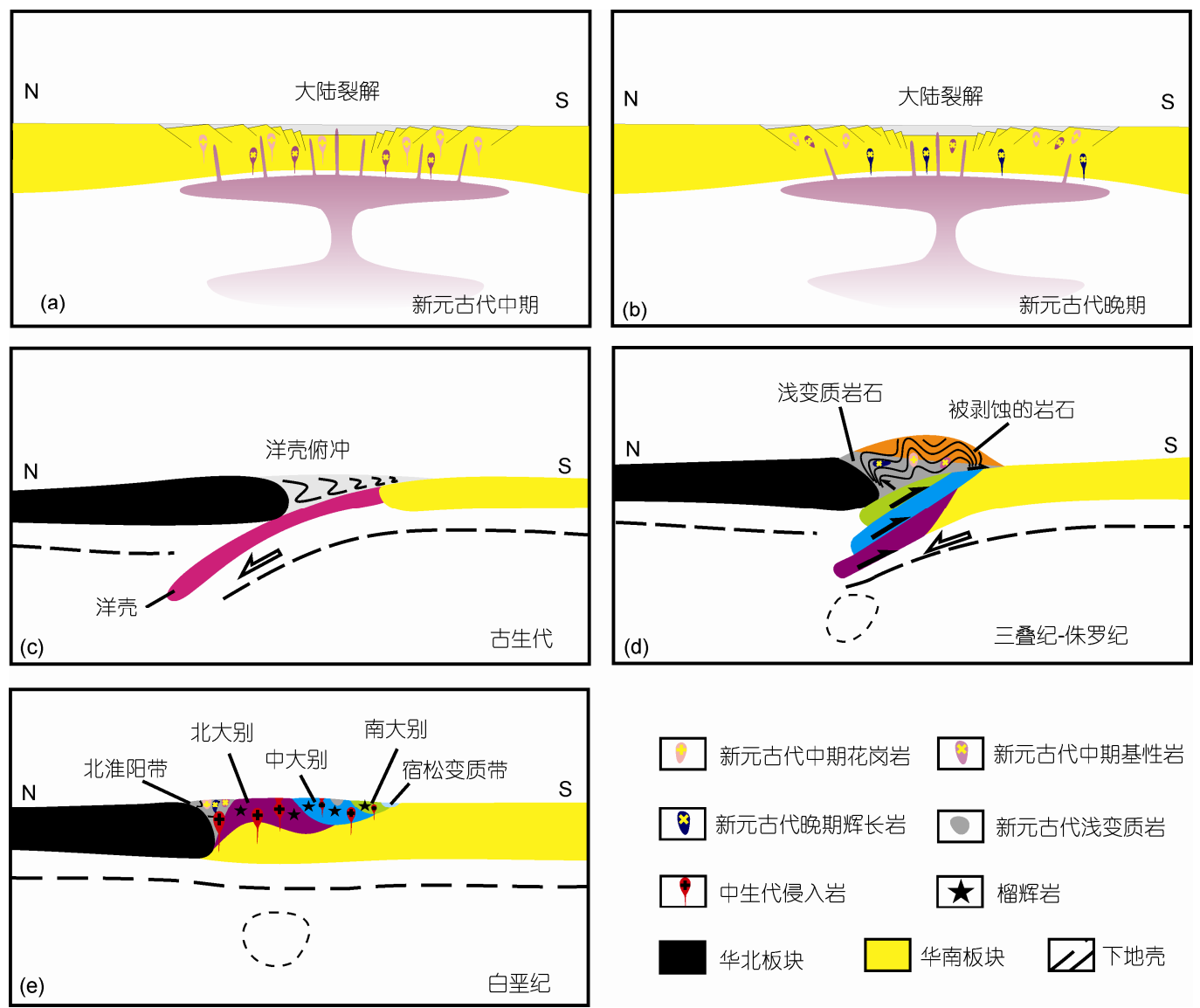

图 3 大别造山带三叠纪低级变质的新元古代花岗岩和基性岩的形成与就位机制模式简图

据文献[45]修改. (a)和(b) 新元古代中、晚期的大陆裂解与岩浆活动阶段; (c) 古生代洋壳俯冲阶段; (d) 三叠纪-侏罗纪大陆俯冲与折返 阶段; (e) 白严纪碰撞后造山阶段

另一方面，进一步证明它们是印支期华南陆块发生 俯冲的初始阶段最早被拆离解耦的岩片，在南北陆 块汇聚、碰撞造山过程中被推覆到华北陆块南缘古生
代浅变质岩系之上或以飞来峰的形式存在于超高压 带中. 大别山三叠纪低级变质的新元古代火成岩的 形成与就位过程, 可以大致归纳为 5 个阶段(图 3).

\section{参考文献}

1 Sobolev N V, Shatsky V S. Diamond inclusions in garnets from metamorphic rocks: A new environment for diamond formation. Nature, 1990, 343: 742-746

2 Xu S T, Okay A I, Ji S, et al. Diamond from the Dabie Shan metamorphic rocks and its implication for tectonic setting. Science, 1992, 256: $80-82$

3 刘贻灿, 李曙光. 俯冲陆壳内部的拆离和超高压岩石的多板片差异折返: 以大别-苏鲁造山带为例. 科学通报, 2008, 53: 2153-2165

4 郑永飞. 超高压变质与大陆碰撞研究进展: 以大别-苏鲁造山带为例. 科学通报, 2008, 53: 2129-2152

5 徐树桐, 刘贻灿, 江来利, 等. 大别山造山带的构造几何学和运动学. 合肥: 中国科学技术大学出版社, 2002. 1-133

6 Zheng Y F, Zhou J B, Wu Y, et al. Low-grade metamorphic rocks in the Dabie-Sulu orogenic belt: A passive-margin accretionary wedge deformed during continent subduction. Int Geol Rev, 2005, 47: 851-871

7 Liu Y C, Li S, Gu X F, et al. Ultrahigh-pressure eclogite transformed from mafic granulite in the Dabie orogen, east-central China. J Metamorph Geol, 2007, 25: 975-989

8 董树文, 王小风, 黄德志. 大别山超高压变质带内浅变质岩片的发现及意义. 科学通报, 1996, 41: 815-820 
9 高天山, 汤加富, 桑海清, 等. 大别山腹地浅变质岩层中富硅凝灰岩 $\mathrm{Ar}-\mathrm{Ar}$ 年龄及其地质意义. 科学通报, 2006, 51: 1197-1202

10 Tang J, Zheng Y F, Wu Y B, et al. Zircon SHRIMP U-Pb dating, C and O isotopes for impure marbles from the Jiaobei terrane in the Sulu orogen: Implication for tectonic affinity. Precambrian Res, 2006, 144: 1-18

11 Hacker B R, Ratschbacher L, Webb L, et al. Exhumation of ultrahigh-pressure continental crust in east central China: Late Triassic-Early Jurassic tectonic unroofing. J Geophys Res, 2000, 105: 13339-13364

12 Huang J, Zheng Y F, Zhao Z, et al. Melting of subducted continent: Element and isotopic evidence for a genetic relationship between Neoproterozoic and Mesozoic granitoids in the Sulu orogen. Chem Geol, 2006, 229: 227-256

13 Liu X C, Jahn B M, Liu D Y, et al. SHRIMP U-Pb zircon dating of a metagabbro and eclogites from western Dabieshan (Hong'an Block), China, and its tectonic implications. Tectonophysics, 2004, 394: 171-192

14 江来利, Siebel W, 陈福坤, 等. 大别造山带北部卢镇关杂岩的 U-Pb 锆石年龄. 中国科学 D 辑：地球科学, 2005, 35: 411-419

15 Zheng Y F, Wu Y B, Chen F K, et al. Zircon U-Pb and oxygen isotope evidence for a large-scale ${ }^{18} \mathrm{O}$ depletion event in igneous rocks during the Neoproterozoic. Geochim Cosmochim Acta, 2004, 68: 4145-4165

16 刘贻灿, 李曙光, 古晓锋, 等. 北淮阳王母观橄榄辉长岩的锆石 SHRIMP U-Pb 年龄及其地质意义. 科学通报, 2006, 51: 2175-2180

17 刘贻灿, 刘理湘, 古晓锋, 等. 大别山北淮阳带西段新元古代浅变质花岗岩的发现及其大地构造意义. 科学通报, 2010, 55: 2391-2399

$18 \mathrm{Wu}$ Y B, Zheng Y F, Tang J, et al. Zircon U-Pb dating of water-rock interaction during Neoproterozoic rift magmatism in South China. Chem Geol, 2007, 246: 65-86

19 Rowley D B, Xue F, Tucker R D, et al. Ages of ultrahigh pressure metamorphism and protolith orthogneisses from the eastern Dabie Shan: U-Pb zircon geochronology. Earth Planet Sci Lett, 1997, 151: 191-203

20 Hacker B R, Ratschbacher L, Webb L, et al. U-Pb zircon ages constrain the architecture of the ultrahigh-pressure Qinling-Dabie orogen, China. Earth Planet Sci Lett, 1998, 161: 215-230

21 Zheng Y F, Fu B, Gong B, et al. Stable isotope geochemistry of ultrahigh pressure metamorphic rocks from the Dabie-Sulu orogen in China: Implications for geodynamics and fluid regime. Earth Sci Rev, 2003, 62: 105-161

22 Liu Y C, Li S, Xu S T. Zircon SHRIMP U-Pb dating for gneiss in northern Dabie high T/P metamorphic zone, central China: Implication for decoupling within subducted continental crust. Lithos, 2007, 96: 170-185

23 Liu Y C, Gu X, Li S, et al. Multistage metamorphic events in granulitized eclogites from the North Dabie complex zone, central China: Evidence from zircon U-Pb age, trace element and mineral inclusion. Lithos, 2011, 122: 107-121

24 洪吉安,马斌，黄琦．湖北柊阳大阜山镁铁/超镁铁杂岩体与金红石矿床成因. 地质科学, 2009, 44: 231-244

25 薛怀民, 马芳, 宋永勤. 扬子克拉通北缘随(州)-菄(阳)地区新元古代变质岩浆岩的地球化学和 SHRIMP 锆石 U-Pb 年代学研究. 岩 石学报, 2011, 27: 1116-1130

26 Wang M, Wang C Y, Sun Y. Mantle source, magma differentiation and sulfide saturation of the $\sim 637$ Ma Zhouan mafic-ultramafic intrusion in the northern margin of the Yangtze Block, Central China. Precambrian Res, 2013, 228: 206-222

27 Li S, Huang F, Nie Y, et al. Geochemical and geochronological constrains on the suture location between the North and South China Blocks in the Dabie orogen, central China. Phys Chem the Earth (A), 2001, 26: 655-672

28 Sun W D, Williams I S, Li S G. Carboniferous and Triassic eclogites in the western Dabie Mountains, east-central China: Evidence for protracted convergence of the North and South China Blocks. J Metamorph Geol, 2002, 20: 873-886

29 Liu X C, Wei C, Li S, et al. Thermobaric structure of a traverse across western Dabieshan: Implications for collision tectonics between the Sino-Korean and Yangtze cratons. J Metamorph Geol, 2004, 22: 361-379

30 Cheng H, King R L, Nakamura E, et al. Transitional time of oceanic to continental subduction in the Dabie orogen: Constraints from U-Pb, Lu-Hf, Sm-Nd and Ar-Ar multichronometric dating. Lithos, 2009, 110: 327-342

31 叶伯丹, 简平, 许俊文, 等. 桐柏-大别造山带北坡苏家河地体拼接带及其构成和演化. 武汉: 中国地质大学出版社, 1993. 1-81

32 Liu Y C, Li Y, Liu L, et al. Neoproterozoic low-grade metagranites and metabasites in the Dabie orogen: Implications for detachment within subducted continental crust and multi-slice exhumation. Acta Geol Sin, 2013, 87(Suppl): 499-502

33 Liu J B, Ye K, Maruyama S, et al. Mineral inclusions in zircon from gneisses in the ultrahigh-pressure zone of the Dabie Mountains. J Geol, 2001, 109: 523-535

34 Zheng Y F, Zhao Z F, Wu Y B, et al. Zircon U-Pb age, Hf and O isotope constraints on protolith origin of ultrahigh-pressure eclogit and gneiss in the Dabie orogeny. Chem Geol, 2006, 231: 135-158

35 Xia Q, Zheng Y F, Hu Z C. Trace elements in zircon and coexisting minerals from low-T/UHP metagranite in the Dabie orogen: Implications for action of supercritical fluid during continental subduction-zone metamorphism. Lithos, 2010, 114: 385-412

36 Tomaschek F, Kennedy A K, Villa I M, et al. Zircons from Syros, Cyclades, Greece-Recrystallization and mobilization of zircon during high pressure metamorphism. J Petrol, 2003, 44: 1977-2002 
37 Liu X C, Jahn B M, Dong S, et al. Neoproterozoic granitoid did not record ultrahigh-pressure metamorphism from the southern Dabieshan of China. J Geol, 2003, 111: 719-732

38 Zheng Y F. Fluid regime in continental subduction zones: Petrological insights from ultrahigh-pressure metamorphic rocks. J Geol Soc London, 2009, 166: 763-782

39 李曙光，黄方，周红英，等. 大别山双河超高压变质岩及北部片麻岩的 U-Pb 同位素组成一对超高压岩石折返机制的制约. 中国 科学 D 辑: 地球科学, 2001, 31: 977-984

40 Zhang H F, Gao S, Zhang Z Q, et al. Geochemical and Sr-Nd-Pb isotopic compositions of Cretaceous granitoids: Constraints on tectonic framework and crustal structure of the Dabieshan ultrahigh-pressure metamorphic belt, China. Chem Geol, 2002, 186: 281-299

41 Zheng Y F, Chen R X, Zhao Z F. Chemical geodynamics of continental subduction-zone metamorphism: Insights from studies of the Chinese Continental Scientific Drilling (CCSD) core samples. Tectonophysics, 2009, 475: 327-358

42 Li Z X, Li X H, Kinny P D, et al. Geochronology of Neoproterozoic syn-rift magmatism in the Yangtze Craton, South China and correlations with other continents: Evidence for a mantle superplume that broke up Rodinia. Precambrian Res, 2003, 122: 85-109

43 Zhang S B, Zheng Y F. Formation and evolution of Precambrian continental lithosphere in South China. Gondwana Res, 2013, 23: $1241-1260$

44 Li S, Kusky T M, Zhao G, et al. Thermochronological constraints on two-stage extrusion of HP/UHP terranes in the Dabie-Sulu orogen, east-central China. Tectonophysics, 2011, 504: 25-42

45 刘贻灿, 刘理湘, 古晓锋, 等. 大别山北淮阳带西段新元古代浅变质岩片的岩石组成及其大地构造意义. 地质科学, 2011 , 46: 273-287 